\title{
Metabolic dependencies govern microbial syntrophies during methanogenesis in an anaerobic digestion ecosystem
}

\author{
Xinyu Zhu ${ }^{1,2}$, Stefano Campanaro ${ }^{3,4}$, Laura Treu ${ }^{1,3^{*}}$, Rekha Seshadri', Natalia Ivanova ${ }^{2}$, Panagiotis G. Kougias ${ }^{1,5^{*}}$ (D)
} Nikos Kyrpides ${ }^{2}$ and Irini Angelidaki ${ }^{1}$

\begin{abstract}
Methanogenesis, a biological process mediated by complex microbial communities, has attracted great attention due to its contribution to global warming and potential in biotechnological applications. The current study unveiled the core microbial methanogenic metabolisms in anaerobic vessel ecosystems by applying combined genome-centric metagenomics and metatranscriptomics. Here, we demonstrate that an enriched natural system, fueled only with acetate, could support a bacteria-dominated microbiota employing a multi-trophic methanogenic process. Moreover, significant changes, in terms of microbial structure and function, were recorded after the system was supplemented with additional $\mathrm{H}_{2}$. Methanosarcina thermophila, the predominant methanogen prior to $\mathrm{H}_{2}$ addition, simultaneously performed acetoclastic, hydrogenotrophic, and methylotrophic methanogenesis. The methanogenic pattern changed after the addition of $\mathrm{H}_{2}$, which immediately stimulated Methanomicrobia-activity and was followed by a slow enrichment of Methanobacteria members. Interestingly, the essential genes involved in the Wood-Ljungdahl pathway were not expressed in bacterial members. The high expression of a glycine cleavage system indicated the activation of alternative metabolic pathways for acetate metabolism, which were reconstructed in the most abundant bacterial genomes. Moreover, as evidenced by predicted auxotrophies, we propose that specific microbes of the community were forming symbiotic relationships, thus reducing the biosynthetic burden of individual members. These results provide new information that will facilitate future microbial ecology studies of interspecies competition and symbiosis in methanogenic niches.
\end{abstract}

Keywords: Anaerobic digestion, Microbial community, Metagenomics, Metatranscriptomics, Auxotrophies, Syntrophic acetate oxidation, Glycine cleavage, Methanogenic pathways

\section{Background}

Microbial methanogenic metabolism is considered as one of the oldest bio-activities on earth and draws great attention because of its global warming potential [1] , which is 28 times higher than carbon dioxide $\left(\mathrm{CO}_{2}\right)$ on a 100-year horizon [2]. In a natural ecosystem, around one billion tons of methane $\left(\mathrm{CH}_{4}\right)$ is formed through microbial activity as an intermediate step of the global carbon cycle [3]. Nevertheless, an enhanced and well-controlled methanogenic process has implications for energy generation [4] due to its high calorific value. Microbial

\footnotetext{
*Correspondence: latr@env.dtu.dk; panak@env.dtu.dk

'Department of Environmental Engineering, Technical University of Denmark, Building 115, DK-2800 Kgs. Lyngby, Denmark

Full list of author information is available at the end of the article
}

methanation was extensively employed in vessel ecosystems, i.e. biogas reactors, to attain large-scale production as a sustainable energy source. It is postulated that methanogenesis is performed mainly through acetoclastic, hydrogenotrophic, and secondary through methylotrophic pathways in oxygen-depleted environments. The known methanogenic members belong mainly to phylum Euryarchaeota, with few exceptions, which were recently assigned to candidate phyla "Bathyarchaeota" [5] and "Verstraetearchaeota" [6]. All methanogens are physiologically specialized and able to scavenge the electrons from hydrogen $\left(\mathrm{H}_{2}\right)$, formate, methanol, and acetate, having $\mathrm{CH}_{4}$ as the final product. Archaeal growth and activity can create ecological niches for the oxidizing

(c) The Author(s). 2020 Open Access This article is distributed under the terms of the Creative Commons Attribution 4.0 International License (http://creativecommons.org/licenses/by/4.0/), which permits unrestricted use, distribution, and 
( $\mathrm{H}_{2}$ producing) bacteria, and form syntrophic relations in a complex community.

In the past years, genome-centric metagenomics was extensively used to describe complex syntrophic microbial communities, and successfully revealed essential knowledge regarding the microbial functions of the keystone species mainly based on their gene profiles $[7,8]$. The majority of studies regarding methanogenic process were focused on specific microbes contributing to the degradation of recalcitrant substrates [9] or the involvement of rare taxon in the methanogenic process $[10,11]$, while few attempts have been made to underlie the basic mechanisms of microbial

community assembly and function $[7,12,13]$. In natural ecosystems, the holistic untangling of the intricate methanogenic process was hampered by the inextricable influence of numerous environmental variables occurring simultaneously. Moreover, the in-situ activity of the individual members in microbial communities and the ecological relationships existing among microbes were extremely difficult to elucidate during the digestion of complexed substrates. Thus, simplified model systems are required to unveil the fundamental metabolic insights into methanogenic activities. A previous study dissected the complex methanogenic consortium into tractable model sections by substrates specification in continuous reactor operation and successfully assigned putative functional roles to the de-novo reconstructed genomes [12]. However, a crucial limitation of studies based solely on metagenomic surveys is the lack of direct evidence for the activity of individual microbes. Therefore, other -omics approaches and advanced molecular tools, such as transcriptomics, proteomics, metabolomics, and stable isotope labelling were gradually introduced to analyze the microbial activity during the methanogenic process [14-17].

The current study is dedicated to unveil the core microbial methanogenic metabolisms with combined genome-centric metagenomic and metatranscriptomic strategies. The methanogenic metabolism was favoured in microcosms where the microbial communities were simplified by providing a chemically-defined substrate (acetate). The study revealed the in situ activity of methanogens in syntrophic microbial communities and their affinity to $\mathrm{H}_{2}$ provision. Moreover, this work also provided mechanistic understandings of the bacterial functionalities both for acetate oxidation and revealed important auxotrophic dependencies, as well as community structure maintenance during methanogenesis.

\section{Materials and methods}

\section{Experimental set-up}

The triplicate lab-scale biogas continuous stirred-tank reactors (working volume 1.8L) were inoculated with digestate from full-scale thermophilic biogas plant (Snertinge, Denmark). The plant was fed with $70-90 \%$ animal manure and $10-30 \%$ food industrial organic waste; therefore, the inoculum provided the microbial community to adopt to heterogeneous substrate degradation. During the experiment, the reactors were fed with synthetic medium, in which only acetic acid was supplied as an organic carbon source. Other nutrients were provided by basal anaerobic medium [18]. The reactors operated under thermophilic condition $\left(55^{\circ} \mathrm{C}\right)$ and the operational parameters were chosen according to empirical experiences of highly efficient thermophilic biogas reactors, i.e. the organic loading rate was $1 \mathrm{~g}$ acetic acid/day. L-reactor and the hydraulic retention time was 15 days. The reactors were fed four times per day with peristaltic pumps to achieve the desired organic loading rate and HRT. Once the reactors reached the steady state, $\mathrm{H}_{2}$ gas was supplemented to each reactor with two stainless steel diffusers (pore size $2 \mu \mathrm{m}$ ) at the rate of $1 \mathrm{~mL} / \mathrm{min}$. To ensure efficient $\mathrm{H}_{2}$ utilization, the gas phase of the reactors was constantly recirculated into liquid phase with peristaltic pumps. Throughout the experiment, biogas production was recorded with water-replacement gas metres; biogas composition was measured using a gas chromatograph (Mikrolab, Aarhus A/S, Denmark), equipped with a thermal conductivity detector (TCD). The volatile fatty acids and ethanol were measured with a gas chromatograph (Shimadzu GC-2010 AF, Kyoto, Japan), equipped with a flame ionization detector (FID) [19]. Biomass formation was estimated through volatile suspended solids measured according to the Standard Methods for the Examination of Water and Wastewater [20]. All determinations and measurements were done in triplicate samples.

\section{Sample collection and sequencing}

The liquid samples were acquired from the triplicate reactors before, 18 hours after and 36 days after $\mathrm{H}_{2}$ addition (Sample point 1, 2, and 3, respectively). For all the samples, the genomic DNA was extracted with PowerSoil ${ }^{\circ}$ DNA Isolation Kit and the total RNA was extracted PowerMicrobiome ${ }^{\circ}$ RNA Isolation Kit (Mo Bio Laboratories, Inc., Carlsbad, USA). All the extractions were performed with additional phenol cleaning steps in order to improve the quality of the extractives. The ribosome RNA was removed from total RNA samples with Ribo-Zero ${ }^{\circ}$ rRNA Removal Kit (Bacteria) (Illumina, San Diego, USA). The DNA and RNA samples were sent to Ramaciotti Centre for Genomics (UNSW, Sydney, Australia) for cDNA construction, library preparation, and sequencing (Illumina NextSeq).

\section{Genome-centric metagenomics}

The DNA sequences from 9 samples were filtered with Trimmomatic software [21], co-assembled with 
metaSPAdes [22], and atomically binned with MetaBAT [23]. The quality of the metagenome-assembled genomes (MAGs) were examined with CheckM [24] and evaluated with a MAG quality standard developed by Genomic Standards Consortium [25]. The average nucleotide identity analysis (ANI) was performed against all the genomes that were deposited in NCBI Reference Sequence Database [26]. The genomes hits with ANI higher than $97 \%$ were used to classify the MAGs at the species level $[27,28]$. The putative taxonomy classification of the unclassified MAGs were further assessed based on ubiquitous proteins with PhyloPhlAn [29]. The genes of the co-assembled metagenome were predicted and annotated with Integrated Microbial Genomes \& Microbiomes (IMG) [30]. For more comprehensive methanogenic pathway reconstruction, all archaeal MAGs were resubmitted to IMG as genomes assembled from metagenome for gene prediction and annotation.

The microbial communities were profiled through reads recruitment from the sequencing samples. The average coverage of MAGs in each metagenome sample was calculated based on the number of reads aligned by Bowtie2 [31] and the detailed procedure were described by Campanaro et al. (2016) [32]. The relative abundance of the MAGs in a community was determined with the average coverage of the MAG in one metagenome sequencing sample, according to:

$$
\begin{aligned}
& \text { Relative abundance }(M A G)_{\text {sample } 1} \\
& =\frac{\text { average coverage }(M A G)}{\sum_{\text {All MAGs in sample } 1 \text { average coverage }}}
\end{aligned}
$$

\section{Genome-dissected metatranscriptomics}

The sequenced transcripts were aligned to assembled metagenomes with Bowtie 2 and quantified with HTSeqcount [31,33]. Therefore, instead of de-novo assembling the RNA sequences, the metatranscriptomes inherited the annotation from the corresponding metagenomes. The expression level of genes was evaluated by reads per reads per kilobase of exon model per million mapped reads (RPKM) [34].For comparison purpose, the RPKM numbers were normalized considering the expression level of methyl-coenzyme $\mathrm{M}$ reductase gene (subunit alpha) and $\mathrm{CH}_{4}$ production rates of the reactors during the time that each sample was collected. Moreover, the metatranscriptomes were dissected according to the binning results in order to generate individual expression profiles for MAGs. The overall activity of a MAG was evaluated by the average gene RPKM within the genome. The relative activity of MAGs in a community was measured according to a similar formula as relative abundance:

$$
\begin{aligned}
& \text { Relative abundance (MAG) })_{\text {sample } 1} \\
& =\frac{\text { average gene RPKM }(M A G)}{\Sigma_{\text {All MAGs in sample } 1 \text { average gene } R P K M}}
\end{aligned}
$$

The comparison between the relative abundance and activity of a MAG suggested its activity level. More specifically, a low abundance/ activity ratio represented an active member, who undertook many microbial metabolisms with few numbers of cells. The overall microbial community composition was visualized by Anvi'o [35].

The gene expression profiles derived from genomedissected metatranscriptome were also used to indicate the functional role of each MAG during the methanogenic process. Genes were categorized based on KEGG modules and the average RPKM of all the genes was calculated for each module. The differential expression of each gene in coordination to the $\mathrm{H}_{2}$ addition was examined using edgeR package [36]. Other statistical tests (Student's t-tests and correlation tests) were performed with Excel.

Specific metabolisms, i.e. methanogenesis and acetate uptake, were tentatively distributed to individual MAGs based on the expression level of signature genes. For instance, the methanogenic activity of individual archaeal MAGs was determined based on the expression level of MAG-specific $m c r A$ comparing to the overall expression of all mcrA [37]. Moreover, MAG-specific acetate kinase (ack) as well as acyl-CoA synthetase (acs) were used to correlate the acetate metabolism to individual members among the microbial community.

\section{Data availability}

The raw sequence data were deposited on sequence read archive with accession no PRJNA525781, The biosample metadata were deposited in Genomes OnLine Database (GOLD) as study Gs0128993.The metagenome annotation was deposited as analysis project $\mathrm{Ga} 0214976$. The annotation of methanogen MAGs was deposited as analysis projects Ga0214977, Ga0214981, Ga0214989, $\mathrm{Ga} 0214990$ and $\mathrm{Ga} 0214991$.

\section{Results}

Methanogenic microcosms enriched by acetate and $\mathrm{H}_{2}$ The tractable low-complexity methanogenic microbial communities were obtained from triplicate lab-scale continuous biogas reactors operated under thermophilic conditions providing acetate as the only organic carbon source. After establishment of stable conditions, external $\mathrm{H}_{2}$ gas was injected into all reactors with stainless steel diffusers to assess the microbes' affinity to $\mathrm{H}_{2}$ partial pressure. During the entire experimental operation, the $\mathrm{pH}$ in each reactor was self-stabilized within the optimal range of methanogenesis (7-7.5). The triplicate reactors performed consistently during the two steady 
operational conditions (Sample Points 1 and 3). Nevertheless, a significant discrepancy among triplicate reactors was observed during the transition before and after $\mathrm{H}_{2}$ addition (Sample Point 2), which was mainly attributed to the instability of the microbial community adaptation process. $\mathrm{CH}_{4}$, along with inorganic carbon compounds including $\mathrm{CO}_{2}$, bicarbonate $\left(\mathrm{HCO}_{3}{ }^{-}\right)$and carbonate $\left(\mathrm{CO}_{3}{ }^{2-}\right)$, were the main digestion products. The digestion profiles are described as mol of carbon contained in each products (Fig. 1). In addition, approximately $4 \%$ of carbon ( $\mathrm{mol}$ of carbon in biomass / mol as carbon in acetate) was used to build microbial biomass. The methanation process was extremely efficient as, less than $0.5 \%$ of the carbon ( $\mathrm{mol}$ of carbon in acetate $/ \mathrm{mol}$ as carbon in acetate) left the system as undigested acetate. All of the injected $\mathrm{H}_{2}$ was consumed and the $\mathrm{CH}_{4}$ yield significantly increased from $299.8 \pm 4.4 \mathrm{~mL} / \mathrm{g}$ acetate to $409.3 \pm 14.6 \mathrm{~mL} / \mathrm{g}$ acetate (Fig. 1, Additional file 1).

\section{Metagenome-assembled genome reconstruction and taxonomy assignment}

Samples for shotgun sequencing were collected from triplicate reactors at three time points:1) before $\mathrm{H}_{2}$ addition, 2) 18 hours after $\mathrm{H}_{2}$ addition, and 3) 36 days after $\mathrm{H}_{2}$ addition. Point 1 and Point 3 were chosen during the operational steady states where the $\mathrm{CH}_{4}$ production rate of each reactor varied less than $10 \%$ for 10 consecutive days. Sequences from all samples were co-assembled and automatically binned in order to extract metagenome assembled genomes (MAGs). In total, 79 MAGs were extracted with total coverage ranging from $5 \times$ to $9595 \times$ (Fig. 2, Additional File
1). According to the completeness and contamination values assessed by CheckM, and the quality standards developed by Genomic Standards Consortium [25], 36 MAGs were assigned to the "high-quality" group, 25 MAGs to the "medium quality" group, and 18 MAGs to the "low quality" group. It is noteworthy that over $95 \%$ of total shotgun sequences including DNA and RNA in all samples, could be aligned to the medium-high quality MAGs, suggesting that the majority of the microbial diversity has been recovered with the assembly and binning process.

Five nearly complete archaeal MAGs were present in the community (> 98\% complete), four out of which were characterized at species level as Methanothermobacter thermautotrophicus [38, 39] DTU592, Methanosarcina thermophila [40] DTU593, Methanoculleus thermophilus [41] DTU608 and Methanobacterium sp. MB 1[42] DTU624 (Additional File 2). The unknown archaeal MAG (unclassified Methanomicrobia DTU639), which was also previously found in biogas reactors [32], could be assigned to a member of class Methanomicrobia based on tentative phylogenetic classification. In contrast to archaeal MAGs, 51 out of 56 bacterial MAGs could only be classified at the family or higher taxonomic level. According to the relative abundance, more than $90 \%$ of the microbial community could be represented by 18 most abundant MAGs, 15 of which belonged to domain Bacteria. Among bacteria, 11 MAGs were assigned to Firmicutes (4 MAGs), Bacteroidetes (2 MAGs) Synergistetes (2 MAGs), Proteobacteria (2 MAGs), and Thermotogae (1 MAG). The remaining four MAGs were unclassified Bacteria spp. (Additional File 3).

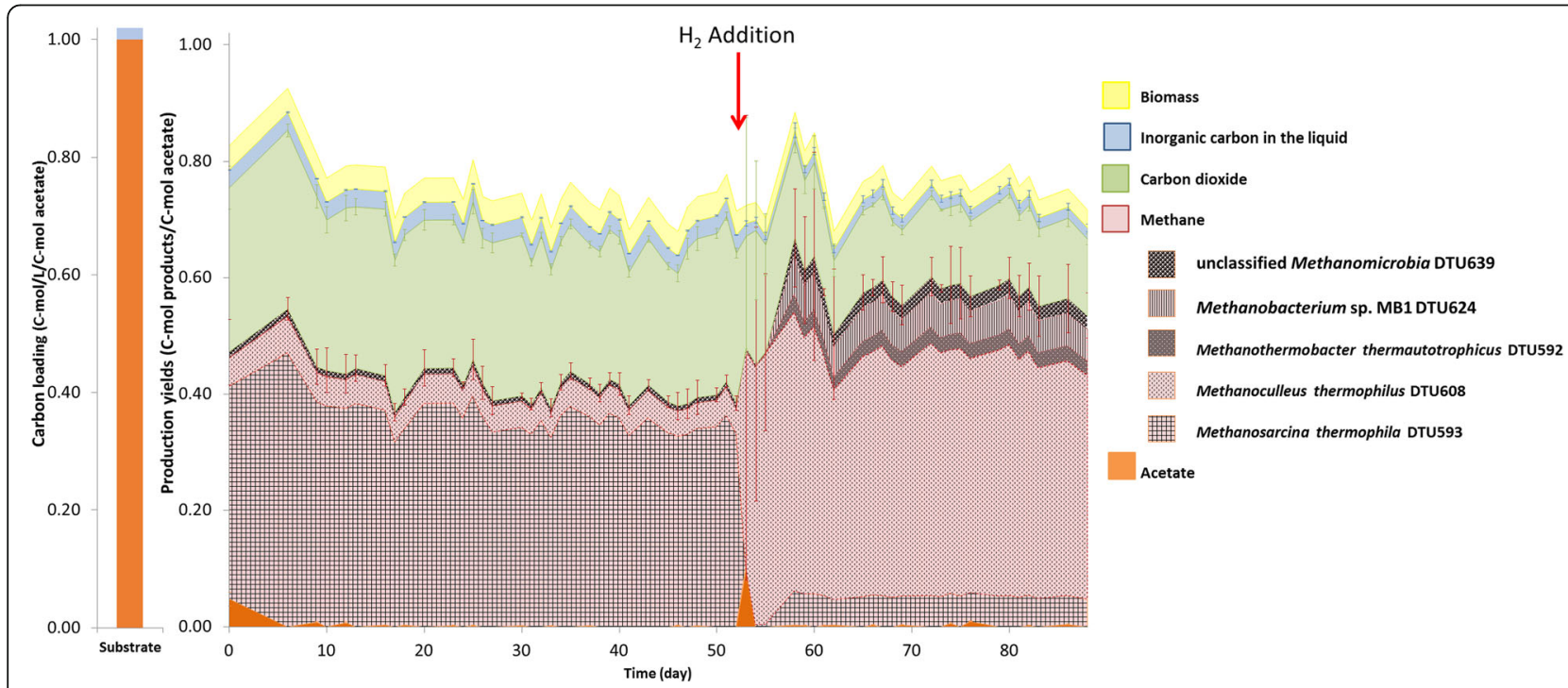

Fig. 1 Digestion profile before and after $\mathrm{H}_{2}$ addition in the reactors. The presented values and standard deviations are calculated from three reactors as biological triplicates. The single bar graph on the left represents the carbon source provided to the system. The $\mathrm{CH}_{4}$ production activity was allocated into five archaeal metagenome-assembled genomes (MAGs) based on the expression level of MAG-specific methyl coenzyme $\mathrm{M}$ reductase gene ( $m c r A$, alpha unit) 


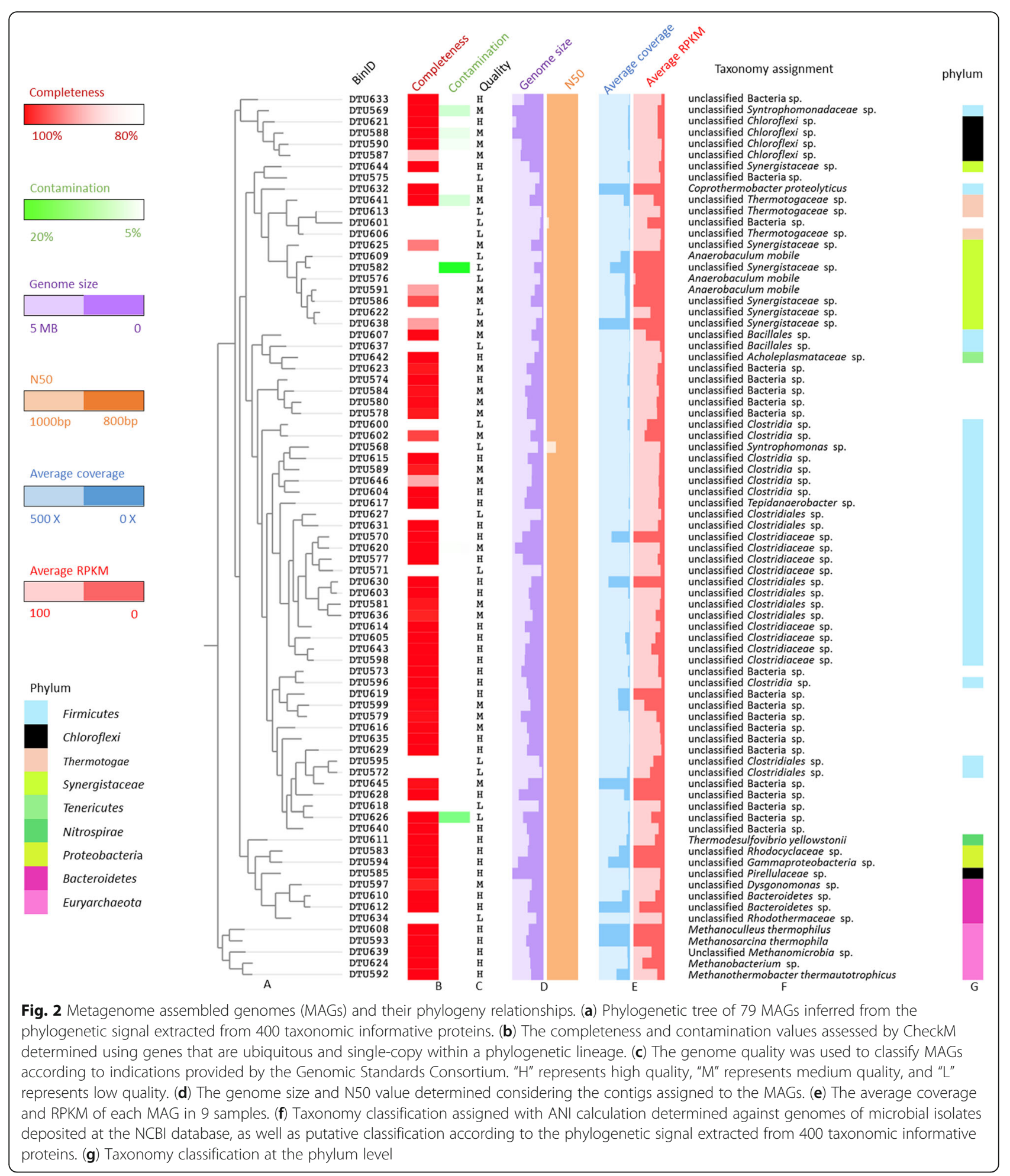

\section{Microbial community composition and transcriptional activity}

The microbial community composition and the transcriptional activity profiles were determined using the average genome coverage of each MAG and the average gene expression level (reads per kb per million mapped reads, RPKM) of all protein-coding genes in each MAG (Fig. 3, Additional File 4 and 5 ). Interestingly, a robust bacterial activity was observed in the reactor, although the present acetoclastic methanogens (M. thermophila 
DTU593) could theoretically undertake the majority of the acetate methanation process. In fact, the five methanogens constituted only a small part of the total microbial community, which is $19-37 \%$ of the abundance and $7-27 \%$ of the activity. It was surprising that methanogens constituted the minority both in respect to relative abundance and activity since only methanogenic substrates (acetate and $\mathrm{H}_{2}-\mathrm{CO}_{2}$ ) were fuelling the process. Before $\mathrm{H}_{2}$ addition, the most abundant MAG (DTU593) among the entire microbial community was classified as Methanosarcina thermophila, accounting for $17 \%$ of the total community (Additional File 4). However, its activity was calculated as $5.3 \%$ among the entire microbial community (Additional File 5). The relatively high RNA/DNA ratio indicated a high cellular protein synthesis potential of $M$. thermophila DTU593 [43], suggesting a possible high growth rate under this condition [44, 45]. In contrast, unclassified Bacteria sp. (DTU645) and unclassified Synergistaceae sp. (DTU638), which were the second and third most abundant MAGs (accounting for 12\% of the community each), were responsible for $19 \%$ and $18 \%$ of the activity respectively (Additional File 4 and 5). After $\mathrm{H}_{2}$ addition, the microbial abundance (based on genome coverage) and transcriptional activity (based on average gene RPKM) profiles changed significantly as a result of community adaptation. The overall archaeal activity changes correlated with the $\mathrm{CH}_{4}$ production rate of the reactor in steady state $\left(R^{2}=0.84\right)$, whereas the correlation between the overall archaeal relative abundance and steady state $\mathrm{CH}_{4}$ production was lower $\left(R^{2}=0.53\right)$ (Additional File 5$)$. In addition to methanogenic archaea, the supplemented $\mathrm{H}_{2}$ also reshaped the bacterial community. The most significant change was the increase of Coprothermobacter proteolyticus DTU632, which became the most abundant MAG, accounting for $19 \%$ of the total community. Interestingly, $C$. proteolyticus DTU632 only contributed to $6.8 \%$ of activity, which was lower than the hydrogenotrophic methanogen $M$. thermophilus DTU608 (18.6\%) and unclassified Bacteria sp. DTU645 (7.2\%) (Additional files 4 and 5).

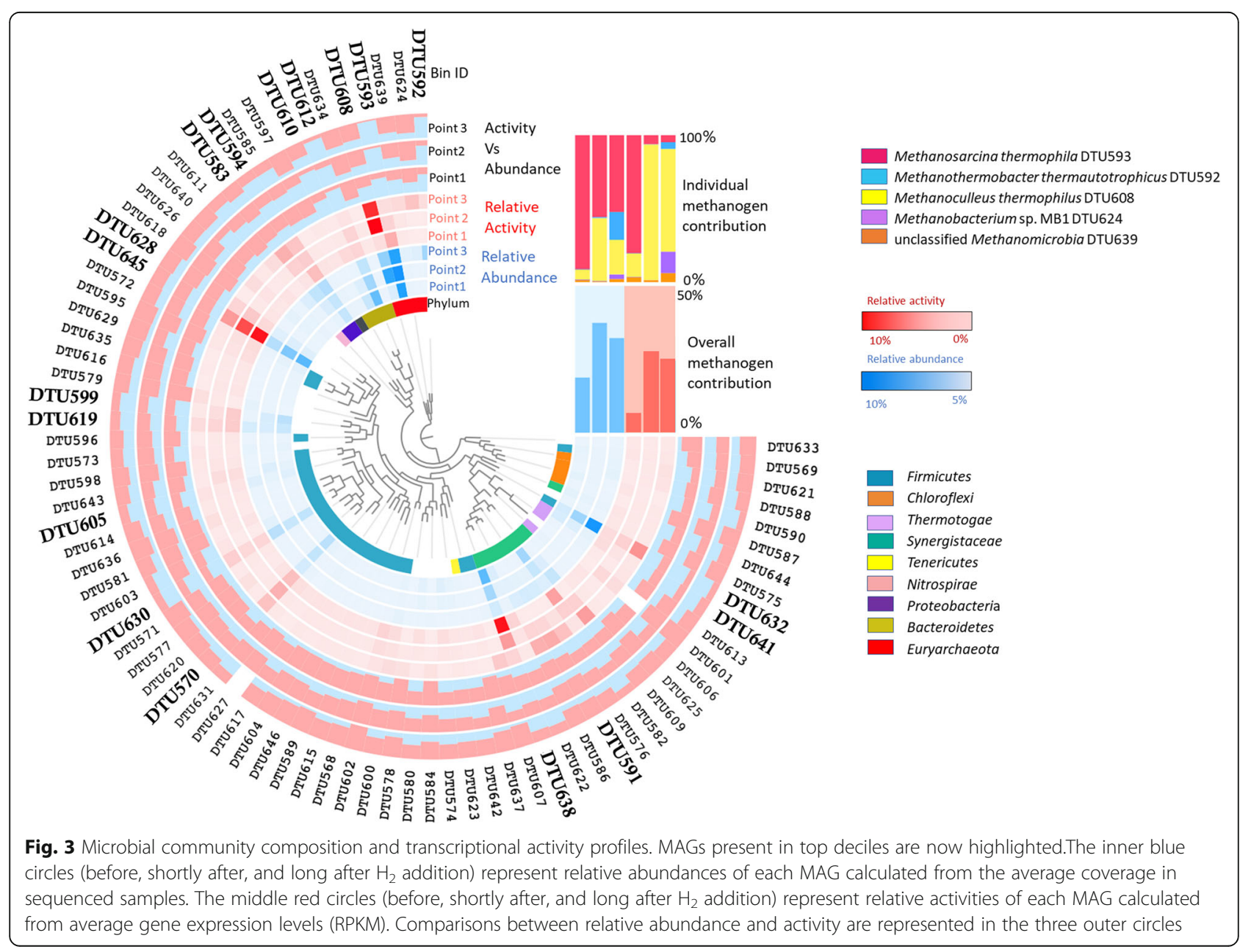




\section{Metabolism of the methanogens}

Acetate, the only organic carbon source supplied to the reactors, was taken up by the microbes through two pathways: inversed phosphotransacetylase-acetate kinase pathway (PTA-ACKA) and AMP-forming acyl-CoA synthetase pathway (AMP-ACS). Thus, acetate utilization by individual microbes could be estimated according to the expression level of MAG-specific acyl-CoA synthetase (acs) and acetate kinase (ack) genes (Additional File 7 ). The main archaeal acetate consumer was M. thermophila DTU593, which consumed less than $50 \%$ of the acetate supplied to the reactors through inversed PTAACKA before $\mathrm{H}_{2}$ addition. After $\mathrm{H}_{2}$ addition, the expression level of $M$. thermophila-specific ack was decreased significantly, while expression of bacterial ack was increased. Considering that $\mathrm{CH}_{4}$ was produced by the five archaea, the methanogenic activity was tentatively distributed among them (expressed as \%) based on the expression level of MAG-specific $m c r A$ (Fig. 2, Additional File 8). Before $\mathrm{H}_{2}$ addition, the methanogenic activity was highest in M. thermophila DTU593 (86\%) and M. thermophilus DTU608 (11\%). After reaching the steady state, external $\mathrm{H}_{2}$ gas was supplied in order to trigger a metabolic shift towards hydrogenotrophic methanogenesis. The amount of $\mathrm{H}_{2}$ injected into the reactor was chosen stoichiometrically to reduce half of the $\mathrm{CO}_{2}$ that was produced from acetate during the methanogenic process. The addition of external $\mathrm{H}_{2}$ gas changed the methanogenic activity of archaeal MAGs. Specifically, the activity of M. thermophilus DTU608 was significantly enhanced and it became the main methanogenic contributor in the microbial community shortly after the $\mathrm{H}_{2}$ addition (98\% of methanogenic activity). By the end of the experiment, the reactor stabilized in a new operational steady state, during which $56 \pm 0.4 \%$ of acetate-carbon was converted to $\mathrm{CH}_{4} \quad(16 \%$ more

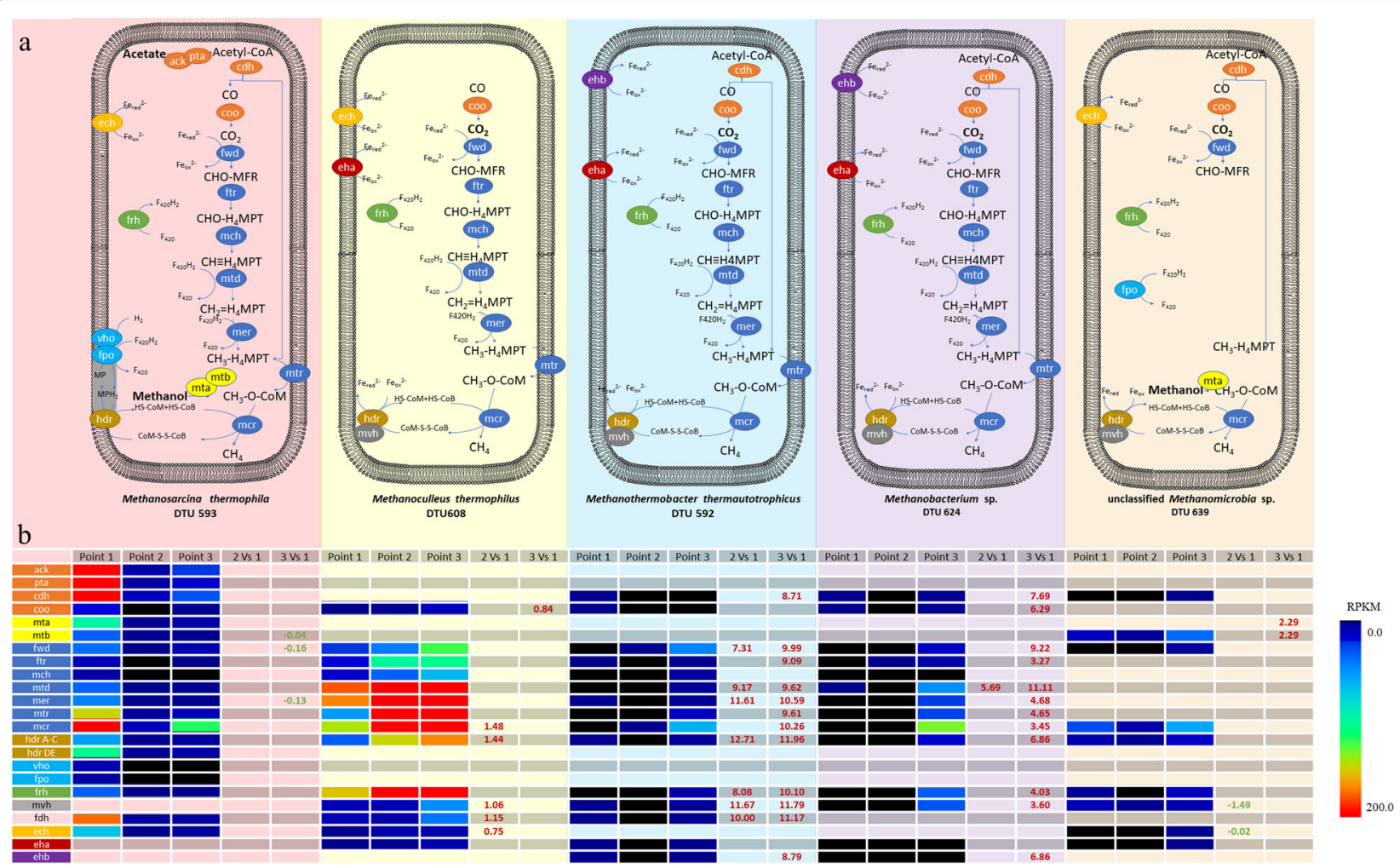

Fig. 4 a Methanogenic pathway reconstructions in five archaeal MAGs. CoA, coenzymeA; MFR, methanofuran; ${ }_{4} M P T$, tetrahydrosarcinapterin; HSCoM, coenzyme M; HS-CoB, coenzyme B; MP, methanophenazine; Fe $e_{\text {, }}$, Ferredoxin; F 420, coenzyme 420; ack, acetate kinase; pta, phosphate acetyltransferase; $c d h$, acetyl-CoA decarbonylase; coo, carbon-monoxide dehydrogenase; mta, methano-specific coenzyme M methyltransferase; mtb, methylamine-specific coenzyme M methyltransferase; fwd, formylmethanofuran dehydrogenase; ftr, formylmethanofuran--

tetrahydromethanopterin $\mathrm{N}$-formyltransferase; mch, methenyltetrahydromethanopterin cyclohydrolase; mtd, methylene tetrahydromethanopterin reductase; mer, $\mathrm{F}_{420}$-dependent methylenetetrahydromethanopterin dehydrogenase; hdr $\mathrm{A}-\mathrm{C}$, heterodisulfide reductase subunits $\mathrm{A}-\mathrm{C}$; hdr $\mathrm{DE}$, heterodisulfide reductase $\mathrm{D}$ and $\mathrm{E}$; vho, methanophenazine-reducing hydrogenase; $f p 0, \mathrm{~F}_{420} \mathrm{H}_{2}$ dehydrogenase; frh, coenzyme $\mathrm{F}_{420}$ hydrogenase subunit; $m v h, F_{420}$-non-reducing hydrogenase; $f d h$, formate dehydrogenase; ech, Escherichia coli hydrogenase 3; eha, energy-converting hydrogenase A; ehb, energy-converting hydrogenase B. $\mathbf{b}$ The expression of genes related to methanogenesis. The colors represent different steps of methanogenic pathways. Significant up (red) and down (green) regulation of genes (evaluated with edgeR) is indicated by colored numbers 
compared with previous states). After long-term adaptation to the $\mathrm{H}_{2}$ addition, although $M$. thermophilus DTU608 maintained its dominance (71\%), a small but significant fraction of methanogenic activity was taken over by $M$. thermophila DTU593 (9\%) and other hydrogenotrophic methanogens (15\%).

Pathways related to methanogenesis and relevant energy conservation systems were reconstructed in all archaeal MAGs (Fig. 4). The expression levels of those genes (normalized according to the expression level of $m c r A$ gene and $\mathrm{CH}_{4}$ production rate) were examined before, shortly after and long after $\mathrm{H}_{2}$ addition (Additional File 8). M. thermophila DTU593 expressed all the genes involved in hydrogenotrophic, methylotrophic and acetoclastic methanogenesis, indicating its multi-trophic functional role in anaerobic digestion. In particular, the expression of methylamine/methanol-specific coenzyme $\mathrm{M}$ methyltransferase genes $(m t a, m t b)$ suggested a considerable contribution of methylotrophic pathways (Additional File 8). For energy conservation, M. thermophila DTU593 obtained the electron from intermediate $\mathrm{H}_{2}$ through methanophenazine-reducing hydrogenase (Vho), coenzyme $\mathrm{F}_{420}$-reducing hydrogenase (Frh), and Escherichia coli hydrogenase $3(E c h)$. The electrons provided by Ech were transferred to ferredoxin and used for $\mathrm{CO}_{2}$ reduction. The electrons carried by $\mathrm{F}_{420} \mathrm{H}_{2}$ were not only used for $\mathrm{CHO}-\mathrm{H}_{4} \mathrm{MPT}$ reduction in hydrogenotrophic methanogenesis but also transferred to methanophenazine through $\mathrm{F}_{420} \mathrm{H}_{2}$ dehydrogenase $(F p o)$. Finally, methanophenazine reduced by Fpo and Vho transferred the electrons to CoM-S-S-CoB through the membranebound heterodisulfide reductase ( $h d r \mathrm{DE}$ ).

In contrast, the methanogenic activity of $M$. thermophilus DTU608 was restricted to hydrogenotrophic pathways (Fig. 4). M. thermophilus DTU608 lacked cytochromes but possessed the electron bifurcation system, which allows coupling $\mathrm{CO}_{2}$ reduction and CoM-SS-CoB reduction with $M v h-H d r$ complex oxidation. In addition, M. thermautotrophicus DTU592 and Methanobacterium sp. gradually increased their relative abundance and activity only after long term operation. These two 'slowly emerged' archaeal MAGs encoded core hydrogenotrophic methanogenesis pathways similar to M. thermophilus DTU608; however, they possessed different hydrogenase complexes for $\mathrm{H}_{2}$ uptake. An important difference is that both $M$. thermautotrophicus DTU592 and Methanobacterium sp. DTU624 used energy converting hydrogenase B $(E h b)$ instead of $E c h$, which was present in M. thermophilus DTU608 (Fig. 4, Additional file 9).

$E h b$ was proven to be related to autotrophic $\mathrm{CO}_{2}$ assimilation, which could confer an advantage to Methanobacteriaceae spp. by increasing its relative abundance in the microbial community during long-term organic carbon starvation [46]. Moreover, both M. thermautotrophicus DTU592 and Methanobacterium sp. DTU624 significantly upregulated carbon monoxide dehydrogenase $(c o o)$ and acetyl-CoA decarbonylase/synthase (Cdh) genes, supporting carbon fixation activity for autotrophic growth (Fig. 4, Additional File 8), while M. thermophilus DTU608 relied on external acetate (heterotrophic) as indicated by the expression of NDP forming acyl-CoA synthetase genes.

\section{Metabolism of the bacteria}

More than $50 \%$ of the acetate, which was not taken up by archaea, was metabolized by bacterial members in the community (Additional File 7). According to the transcriptional activity of formyltetrahydrofolate synthetase gene (fhs), about half of the bacteria community (31 out of 79) were indicated to have a syntrophic lifestyle in association with methanogenic Archaea [47, 48]. Interestingly, the genes encoding the enzyme to directly break the bonds between the carbonyl and methyl branch in the acetate (acetyl-CoA decarbonylase, $c d h$ ) were expressed at an extremely low level (not significant according to edgeR normalization) in all bacterial MAGs (Additional File 10). This result indicated that these bacteria may have acetate utilization pathways other than the conventional Wood-Ljungdahl (WL) pathway, similar to the alternative pathway previously proposed in Thermotogae spp. [49]. High expression levels of ack and glycine decarboxylase genes $(g c v P)$ were found in MAGs belonging to diverse taxa, indicating that the glycine cleavage system proposed for the Thermotogae phylum might be more widely used for bacterial acetate utilization (Additional File 10). Bacteria adopted versatile strategies to transform acetate to glycine, to further metabolize the intermediates released from the glycine cleavage system, as well as to conserve energy. The detailed acetate degradation pathways were proposed based on highly expressed genes (50\% quantile among all the genes expressed in the genome) in the most abundant acetate consuming bacterial MAGs (Fig. 5, Additional File 11, 12 and 13).

The Thermotogae-like acetate utilization pathway was reconstructed in unclassified Bacteria sp. DTU645, which phylogenetically clustered with Firmicutes (Fig. 1). The high expression level of glycine reductase gene ( $\mathrm{grd}$ ) in unclassified Bacteria sp. DTU645 suggested an alternative path for acetate to enter the glycine cleavage system, where acetyl phosphate was directly converted to glycine through reversed glycine reduction (Additional File 11). The glycine reductase gene was found highly expressed in many other bacterial acetate utilizers, e.g. unclassified Synergistaceae sp. DTU638 and C. proteolyticus DTU632 (Additional File 12 and 13). The glycine cleavage system catalysed the decarboxylation of glycine 


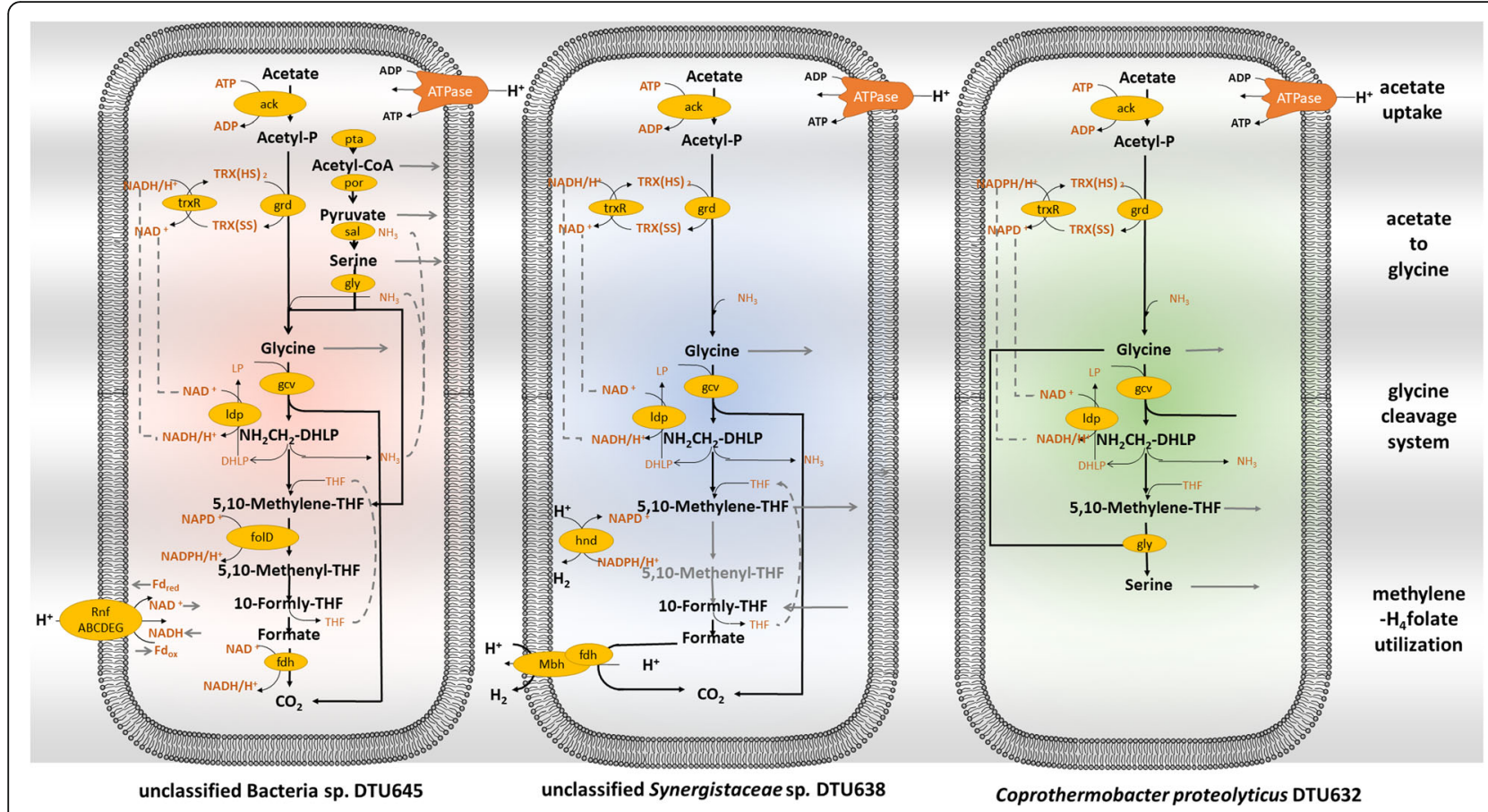

Fig. 5 Acetate utilization pathways in the three most abundant bacterial MAGs. Black arrows represent the reactions mediated by highly expressed genes. Grey arrows represent the metabolites flowing to other metabolic pathways in the cell. Black solid lines represent the reaction mediated by actively expressed genes in the MAG. Grey solid lines represent the metabolites flowing to other metabolic pathways in the cell. Grey dashed arrow lines connect the same compounds/cofactors, which are recirculating in the cell

and released methylene-tetrahydrofolate, $\mathrm{NH}_{3}$ and $\mathrm{CO}_{2}$. The methylene-tetrahydrofolate could be further oxidized through a partial reversed WL pathway in unclassified Synergistaceae sp. DTU638 and unclassified Bacteria sp. DTU645, having $\mathrm{CO} 2$ as the final product (Additional File 11 and 12). Interestingly, the gene set mediating methylene-tetrahydrofolate oxidation was completely absent in C. proteolyticus DTU632, whose genome was $100 \%$ complete according to CheckM (Additional File 2). C. proteolyticus was previously characterized as a proteolytic bacterium that produces acetate, $\mathrm{CO}_{2}$ and $\mathrm{H}_{2}$ as main fermentative products [48]. However, its high relative abundance and activity in this study indicated its involvement in the acetate metabolism with additional $\mathrm{H}_{2}$ supplements. Considering C. proteolyticus is known to metabolize amino acids, a Stickland-like reaction was tentatively reconstructed in strain DTU632 after considering the highly expressed genes (Fig. 5, Additional file 13). Specifically, the methylene-tetrahydrofolate released from the glycine cleavage system was combined with another glycine to create serine, and eventually entered the pathways for amino acid metabolism. In all the proposed pathways, the electrons were balanced from acetate-uptake to glycine decarboxylation, and additional electron disposal was required for further oxidation of methylenetetrahydrofolate. For unclassified Synergistaceae sp.
DTU638, the electron was disposed of as $\mathrm{H}_{2}$ as suggested by the high expression of membrane-bound hydrogenase and Fe-S-cluster-containing hydrogenase (Additional File 12), which explained why $\mathrm{H}_{2}$ inhibited the activity of unclassified Synergistaceae sp. DTU638. As a consequence of external $\mathrm{H}_{2}$ addition, the acetate uptake activity was taken over by unclassified Bacteria spp. Unlike unclassified Synergistaceae sp. DTU638, the formate dehydrogenase operon of unclassified Bacteria sp. DTU645 did not contain a hydrogenase gene (Additional File 11), suggesting the electrons could be disposed of in other forms than $\mathrm{H}_{2}$. This observation explained the increment in relative abundance of DTU645 and other bacterial members after $\mathrm{H}_{2}$ addition.

\section{Overall metabolism of microbial community}

In order to maintain the methanogenic activity of the microbial community, a syntrophic behaviour is needed to synthesize numerous metabolites. The holistic microbial community activity could be evaluated by the average RPKM of genes in each KEGG module. An overall shift of the microbial activity was observed in the majority of the KEGG modules after $\mathrm{H}_{2}$ addition. Specifically, the expression level of the KEGG modules related to methanogenesis, including both reactions directly linked to $\mathrm{CH}_{4}$ formation and biosynthesis of cofactors $\left(\mathrm{F}_{420}\right)$ increased roughly 1.5-fold after $\mathrm{H}_{2}$ addition (Additional 
File 14). Moreover, $\mathrm{H}_{2}$ also enhanced the activity of the glyoxylate cycle and the biosynthesis of lipids and specific amino acids (Additional File 14).

Although both abundance and activity of individual MAGs changed significantly in the different $\mathrm{H}_{2}$ adaptation stages, ubiquitous metabolic pathways were found to be essential for maintaining the complex microbial community. Specifically, the results showed that the core metabolisms carried out by the dominant bacteria community before $\mathrm{H}_{2}$ addition could be maintained by other members proliferating after $\mathrm{H}_{2}$ addition (Additional File 14). These metabolic steps were catalysed by proteins encoded by constitutively expressed genes that maintain basic cellular function, such as biosynthesis, energy conservation, repair, and regulatory systems.

The investigation of each individual MAGs' expression profile showed that the biosynthesis of common cofactors such as coenzyme A, NAD and riboflavin were evenly expressed in the dominant microbes, whereas the biosynthesis of several energy-expensive amino acids [50] and cofactors (such as biotin) were absent from some MAGs (Fig. 6). Specific metabolic traits are suggested for individual microbes based on their gene expression profile. For example, C. proteolyticus DTU632 lacked efficient pathways for electron disposal and energy-efficient acetate catabolism but showed high activity of reductive citric acid cycle. Therefore, $C$. proteolyticus might grow as energy-expensive amino acid auxotrophs to reduce the biosynthetic burden. The high expression of many amino acid transport systems indicated that the growth of $C$. proteolyticus DTU632 was supported by external amino acid uptake, such as tryptophan, tyrosine, and cysteine, (Additional File 13). The expression profiles of unclassified Bacteria sp. DTU628, unclassified Clostridiales sp. DTU630, and unclassified Rhodocyclaceae sp. DTU583 implied that these bacteria could synthesize relevant amino acids during $\mathrm{H} 2$ addition (Fig. 6). Another interesting observation was that the genes involved in the biosynthesis of biotin were only found in unclassified Clostridiaceae sp. DTU570, unclassified Gammaproteobacteria sp. DTU594, and unclassified Clostridiales sp. DTU630. It was previously demonstrated that the growth of some methanogens required an external supply of biotin [51]. Considering the consistent expression of genes encoding biotin-specific transporters in the methanogens, biotin auxotrophy might have forced methanogens to scavenge metabolic products for methanogenesis, thereby leading to syntrophic behaviour between bacteria and archaea.

\section{Discussion}

The combination of genome-centric metagenomics and metatranscriptomics successfully revealed individual functional roles of microbial members in methanogenic microcosms. The results assigned a multi-trophic role to Methanosarcina thermophila, suggesting its ability to perform simultaneous methanogenesis from acetate, $\mathrm{CO}_{2}$ and methanol/ methylamine. Although the use of cytochromes in $M$. thermophila would impose thermodynamic limitations to compete for $\mathrm{H}_{2}$ during low $\mathrm{H}_{2}$ partial pressure [52], Fpo-Hdr mediated heterodisulfide reduction promoted the activity of Frh, leading to the activation of the hydrogenotrophic pathway. Therefore, the $\mathrm{H}_{2}$ produced as an intermediate during anaerobic digestion not only promote the growth of hydrogenotrophic methanogens but also provide a favourable ecological niche for $M$. thermophila. The complex association between acetoclastic methanogens and acetate-oxidising bacteria could be one cause of functional redundancy in microbial communities involved in biomethanation. In this experiment, although M. thermophila had the metabolic potential to perform methanogenesis through a mainly acetoclastic pathway, a bacteria-dominated microbial consortium was formed, which resulted in a multi-trophic methanogenesis strategy. The results also underlined the importance of methanol/ methylamine methanogenic pathways, although significant methanol concentrations were not detected during the process. In fact, the methanol/ methylamine-specific methanogens were previously identified as pivotal members in many other biogas reactors fed with manure [32]. From this result, we believe that the maintenance of the relevant metabolites (such as methanol/methylamine) at low concentration in an efficient anaerobic digestion system. The addition of external $\mathrm{H}_{2}$ greatly enhanced the activity and the relative abundance of hydrogenotrophic methanogens, including $M$. thermophilus, whose activity was inherent in the microbial community before $\mathrm{H}_{2}$ addition and Methanobacteriaceae spp, which was nonexistent before $\mathrm{H}_{2}$ addition but significantly increased later after a long period of adaptation to external $\mathrm{H}_{2}$. The stimulation of Methanomicrobia members was in accordance with previous research, where anaerobic digestion systems were exposed to different $\mathrm{H}_{2}$ partial pressures [53-55]. For instance, a study on biogas biological upgrading systems [54] concluded that the microbial community would turn over from a "Methanoculleus-dominated" microbial community to a "Methanothermobacterdominated" community after a 2-year stable operation with external supplemented $\mathrm{H}_{2}$. Several hypotheses were proposed to explain the methanogens differing affinities to $\mathrm{H}_{2}$ concentration; these hypotheses were based on gene expression regulation, or considered energy conservation strategies and syntrophic associations with bacterial partners [12]. This work suggests that the competition among the different hydrogenotrophic methanogens can be explained by a bargain between methanogenic activity and autotrophic 


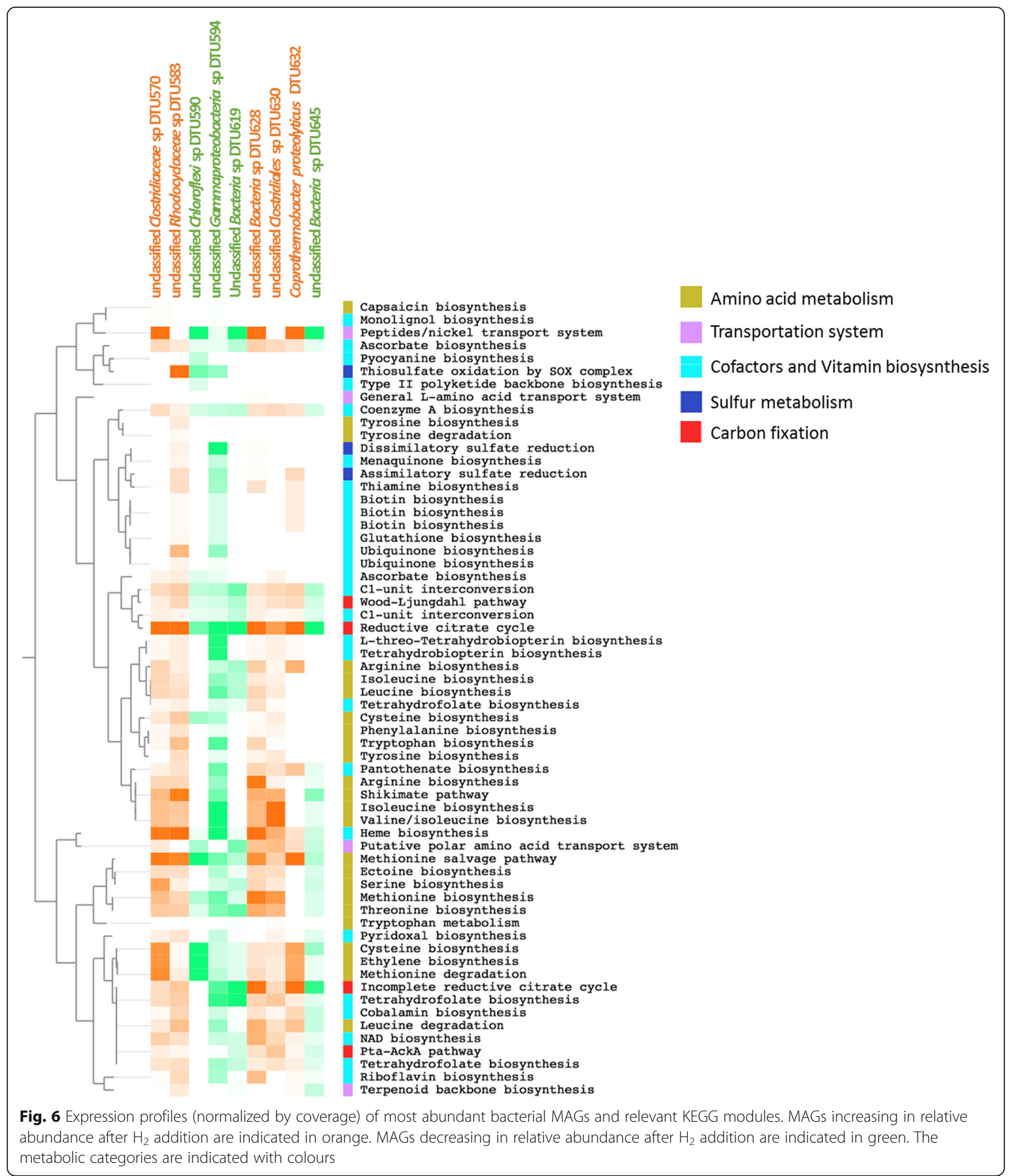

growth. The hydrogenase genes encoded by Methanobacteriaceae spp. (ehb) might especially support growth with external $\mathrm{H}_{2}$ and promote growth during long-term $\mathrm{H}_{2}$ adaptation and limited carbon sources.
The bacterial metabolic pathways were essential for their contribution to acetate oxidation, as well as for their role in maintaining the microbial community structure. Bacterial acetate oxidation under anaerobic conditions is 
postulated to be performed through the reductive WL pathway, which was annotated in the known syntrophic oxidizer, Syntrophaceticus schinkii [56]. However, it was also recently found that many genomes from acetate utilizers, including both MAGs and isolates, possessed only a subset of WL pathway genes $[49,57]$. The results of this study showed extensive use of a glycine cleavage system by many members of the community to circumvent the direct break of the carbonyl and methyl carbon bonds of acetate. The glycine cleavage system could be used in the previously proposed manner, where it was combined with a partial WL pathway to produce $\mathrm{CO}_{2} / \mathrm{H}_{2}$ and support the syntrophic activity with hydrogenotrophic methanogens [49]. Moreover, in the present study, a completely new Stickland-like path was proposed for C. proteolyticus DTU632. Unlike the conventional Stickland reaction where the amino acids were provided to the microbes as a carbon source, in this newly proposed pathway, acetate was converted to glycine which served as both an electron donor and acceptor for further metabolism. The oxidation of carbonyl groups was performed through the glycine cleavage system and the methyl carbons were used for amino acids biosynthesis as previously suggested in organohalide-respiring Dehalococcoides mccartyi [58]. C. proteolyticus's capability to utilize acetate was not revealed in studies performed on pure cultures [59] and this metabolic trait might only be activated under specific conditions. The current experiment imposed a selective pressure on C. proteolyticus, where acetate was the sole organic source, external $\mathrm{H}_{2}$ was supplemented, and microbial partners were present to form syntrophic relationships. This finding encourages future studies to explore metabolic potential in diverse environments and to prove that the functional roles of individual members of a microbial community could go beyond the physiological characterization of the corresponding isolates. Lastly, some crucial transcriptomic activities, such as biosynthesize of amino acids and cofactors, were absent in the most abundant MAGs, which indicated potential exchange of carbon sources, amino acids, and cofactors among bacterial and archaeal members. These results underlined the importance of auxotrophy in the microbial communities, which was previously proposed to reduce biosynthetic burden [60, 61]. This finding may be considered one of the most important reasons for maintaining/forming a complex microbial community even during growth on simple substrates (e.g. acetate). Auxotrophy could also provide explanations for previous observations, as for example, the unexpected proteolytic activity of C. proteolyticus [15], which was observed during cellulose degradation (without protein as substrate), and required an external source of energy-expensive amino acids.

\section{Conclusions}

The combined genome-centric metagenomics and metatranscriptomics strategy used in the present work was extremely informative to characterize unknown microbial communities and elucidate the metabolic activity of individual microbial species. Especially, the distribution of metabolic activities based on genome-dissected metatranscriptomes directly revealed the contribution of individual MAGs to the global activity of the microbiome. The novel microbial insights illustrated in the current study expanded the current knowledge regarding metabolisms in methanogenic systems and the results obtained can open new horizons for future microbial ecology studies of interspecies competition or symbiosis.

\section{Supplementary information}

Supplementary information accompanies this paper at https://doi.org/10. 1186/s40168-019-0780-9.

Additional file 1. The genome quality of all MAGs.

Additional file 2. Hydrogen concentration in gas phase of reactors.

Additional file 3. Average nucleotide identity between MAGs in this study and genomes in NCBI database (hit with $85 \%$ similarity).

Additional file 4. The average coverage and relative abundance of each MAG in 9 samples.

Additional file $\mathbf{5}$. The average RPKM and relative activity of each MAG in 9 samples.

Additional file 6. The correspondence among methane yield, expression of mrcA gene, overall archaeal relative abundance and activity.

Additional file 7. The expression level of acetate kinase, acyl-CoA synthetase and formyltetrahydrofolate synthetase genes.

Additional file 8. Genes used for methanogenic pathway reconstructions in five archaeal MAGs and their regulation towards external hydrogen

Additional file 9. The reconstruction of eha, ehb and ech cluster in different hydrogenotrophic methanogens.

Additional file 10. The expression level of glycine cleavage system $\mathrm{H}$ protein, acetyl-CoA decarbonylase/synthase complex and glycine reductase genes.

Additional file 11. Gene expression profile of unclassified Bacteria sp.DTU645.

Additional file 12. Gene expression profile of unclassified Synergistaceae sp.DTU638.

Additional file 13. Gene expression profile of Coprothermobacter proteolyticus DTU632.

Additional file 14. Average expression level of each KEEG module.
Abbreviations

ack: Acetate kinase gene; acs: Acyl-CoA synthetase gene; AMP-ACS: AMPforming acyl-CoA synthetase pathway; Cdh: Acetyl-CoA decarbonylase/ synthase; coo: Carbon monoxide dehydrogenase gene; Ech: Energy converting hydrogenase; Ehb: Energy-converting hydrogenase $B ; F p o: F_{420} \mathrm{H}_{2}$ dehydrogenase; Frh: Coenzyme $\mathrm{F}_{420}$-reducing hydrogenase; gcv: Glycine decarboxylase genes; grd: Glycine reductase gene; hdr: Membrane-bound heterodisulfide reductase; MAG: Metagenome assembled genome; mcrA: Methyl coenzyme M reductase gene; $m$ ta, $m$ tb: Coenzyme $M$ methyltransferase genes; PTA-ACKA: Phosphotransacetylase-acetate kinase pathway; RPKM: Reads per kilobase of exon model per million mapped reads; Vho: Methanophenazine-reducing hydrogenase; WL: Wood-Ljungdahl 


\section{Acknowledgements}

We thank Hector Garcia and Hector Diaz for technical assistance. Sequencing was performed at the Ramaciotti Centre for Genomics (Sydney, Australia).

\section{Authors' contributions}

XZ monitored bioreactors performance, collected the samples, analysed biochemical parameters, prepared DNA and RNA for sequencing, analysed metagenomic and metatranscriptomic data, and drafted the manuscript; SC designed the strategy for metagenomic and metatranscriptomic data analysis, analysed metagenomic and metatranscriptomic data, wrote per scripts, and revised the manuscript; LT analysed biochemical parameters, designed experiments, the strategy for metagenomic and metatranscriptomic data analysis, and revised the manuscript; RS designed the strategy for metagenomic and metatranscriptomic data; NI designed the strategy for metagenomic and metatranscriptomic data; PGK designed experiments, set up bioreactors, analysed biochemical parameters, and revised the manuscript; NK designed the strategy for metagenomic and metatranscriptomic data analysis, supervised metagenomic and metatranscriptomic data analysis, and revised the manuscript; IA designed and supervised experiments and revised the manuscript. All authors read and approved the final manuscript.

\section{Funding}

This work was supported by the Innovation Fund under the project "SYMBIO - Integration of biomass and wind power for biogas enhancement and upgrading via hydrogen assisted anaerobic digestion," contract 12132654.

\section{Availability of data and materials}

The datasets generated and/or analysed during the current study are available in the sequence read archive (SRA, https://www.ncbi.nlm.nih.gov/ sra) and Genomes OnLine Database (GOLD, https://gold.jgi.doe.gov/) and Integrated Microbial Genomes \& Microbiomes (IMG, https://img.jgi.doe.gov/). Additional data are all provided as Supplementary Datasets in Additional files.

\section{Ethics approval and consent to participate}

Not applicable.

\section{Consent for publication}

Not applicable.

\section{Competing interests}

The authors declare that they have no competing interests.

\section{Author details}

'Department of Environmental Engineering, Technical University of Denmark, Building 115, DK-2800 Kgs. Lyngby, Denmark. US Department of Energy, Joint Genome Institute, Walnut Creek, CA, USA. ${ }^{3}$ Department of Biology, University of Padua, Via U. Bassi 58/b, 35121 Padua, Italy. ${ }^{4}$ CRIBI Biotechnology Center, University of Padua, 35131 Padua, Italy. ${ }^{5}$ Soil and Water Resources Institute, Hellenic Organisation-DEMETER, 57001, ThermiThessaloniki, Greece.

Received: 29 November 2019 Accepted: 27 December 2019 1.

\section{References}

1. Sorokin DY, Makarova KS, Abbas B, Ferrer M, Golyshin PN, Galinski EA, et al. Discovery of extremely halophilic, methyl-reducing euryarchaea provides insights into the evolutionary origin of methanogenesis. Nat Microbiol. Nature Publishing Group. 2017;2:17081.

2. Myhre G, Shindell D, Bréon F-M, Collins W, Fuglestvedt J, Huang J, et al. Anthropogenic and natural radiative forcing. Clim Chang. 2013;423:658-740.

3. Thauer RK, Shima S. Biogeochemistry: Methane and microbes. Nature. Nature Publishing Group; 2006;440:878.

4. Angelidaki I, Karakashev D, Batstone DJ, Plugge CM, Stams AJM. Biomethanation and its potential. Methods Enzymol. Elsevier; 2011. p. 327-51.

5. Evans PN, Parks DH, Chadwick GL, Robbins SJ, Orphan VJ, Golding SD, et al. Methane metabolism in the archaeal phylum Bathyarchaeota revealed by genome-centric metagenomics. Science (80- ). American Association for the Advancement of Science; 2015;350:434-438.

6. Vanwonterghem I, Evans PN, Parks DH, Jensen PD, Woodcroft BJ, Hugenholtz $\mathrm{P}$, et al. Methylotrophic methanogenesis discovered in the archaeal phylum Verstraetearchaeota. Nat Microbiol. Nature Publishing Group; 2016;1:16170

7. Campanaro S, Treu L, Kougias PG, Luo G, Angelidaki I. Metagenomic binning reveals the functional roles of core abundant microorganisms in twelve full-scale biogas plants. Water Res. Elsevier. 2018;140:123-34.

8. Kougias P, Campanaro S, Treu L, Tsapekos P, Armani A, Angelidaki I. Genome-centric metagenomics revealed the spatial distribution and the diverse metabolic functions of lignocellulose degrading uncultured bacteria. bioRxiv. Cold Spring Harbor Laboratory; 2018;328989.

9. Lykidis A, Chen C-L, Tringe SG, McHardy AC, Copeland A, Kyrpides NC, et al. Multiple syntrophic interactions in a terephthalate-degrading methanogenic consortium. ISME J. Nature Publishing Group; 2011;5:122.

10. Kirkegaard RH, Dueholm MS, Mcllroy SJ, Nierychlo M, Karst SM, Albertsen M, et al. Genomic insights into members of the candidate phylum Hyd24-12 common in mesophilic anaerobic digesters. ISME J: Nature Publishing Group; 2016.

11. Stolze Y, Bremges A, Rumming M, Henke C, Maus I, Pühler A, et al. Identification and genome reconstruction of abundant distinct taxa in microbiomes from one thermophilic and three mesophilic production-scale biogas plants. Biotechnol Biofuels. BioMed Central; 2016;9:156.

12. Zhu X, Campanaro S, Treu L, Kougias PG, Angelidaki I. Novel ecological insights and functional roles during anaerobic digestion of saccharides unveiled by genome-centric metagenomics. Water Res. 2019;151.

13. Narihiro T, Nobu MK, Kim N, Kamagata Y, Liu W. The nexus of syntrophyassociated microbiota in anaerobic digestion revealed by long-term enrichment and community survey. Environ Microbiol. Wiley Online Library. 2015;17:1707-20.

14. Fontana A, Kougias PG, Treu L, Kovalovszki A, Valle G, Cappa F, et al. Microbial activity response to hydrogen injection in thermophilic anaerobic digesters revealed by genome-centric metatranscriptomics. Microbiome. BioMed Central; 2018;6:194.

15. Lü F, Bize A, Guillot A, Monnet V, Madigou C, Chapleur O, et al. Metaproteomics of cellulose methanisation under thermophilic conditions reveals a surprisingly high proteolytic activity. ISME J. Nature Publishing Group. 2014;8:88-102.

16. Kindt A, Liebisch G, Clavel T, Haller D, Hörmannsperger G, Yoon H, et al. The gut microbiota promotes hepatic fatty acid desaturation and elongation in mice. Nat Commun. Nature Publishing Group; 2018;9: 3760

17. Singer $\mathrm{E}$, Wagner $\mathrm{M}$, Woyke $\mathrm{T}$. Capturing the genetic makeup of the active microbiome in situ. ISME J. Nature Publishing Group; 2017;11:1949.

18. Angelidaki I, Petersen SP, Ahring BK. Effects of Lipids on Thermophilic Anaerobic-Digestion and Reduction of Lipid Inhibition Upon Addition of Bentonite. Appl Microbiol Biotechnol. 1990;33:469-72.

19. Kougias PG, Boe K, Einarsdottir ES, Angelidaki I. Counteracting foaming caused by lipids or proteins in biogas reactors using rapeseed oil or oleic acid as antifoaming agents. Water Res. Elsevier. 2015:79:119-27.

20. APHA. Standard Methods for the Examination of Water and Wastewater: Stand. Methods. American Public Health Association; 2005.

21. Bolger AM, Lohse M, Usadel B. Trimmomatic: a flexible trimmer for Illumina sequence data. Bioinformatics. 2014:btu170.

22. Nurk S, Meleshko D, Korobeynikov A, Pevzner PA. metaSPAdes: a new versatile metagenomic assembler. Genome Res. Cold Spring Harbor Lab. 2017;27:824-34

23. Kang DD, Froula J, Egan R, Wang Z. MetaBAT, an efficient tool for accurately reconstructing single genomes from complex microbia communities. PeerJ. PeerJ Inc.; 2015;3:e1165.

24. Parks DH, Imelfort M, Skennerton CT, Hugenholtz P, Tyson GW. CheckM: assessing the quality of microbial genomes recovered from isolates, single cells, and metagenomes. Genome Res. Cold Spring Harbor Lab. 2015;25: 1043-55.

25. Bowers RM, Kyrpides NC, Stepanauskas R, Harmon-Smith M, Doud D, Reddy TBK, et al. Minimum information about a single amplified genome (MISAG) and a metagenome-assembled genome (MIMAG) of bacteria and archaea. Nat Biotechnol. 2017;35:725.

26. O'Leary NA, Wright MW, Brister JR, Ciufo S, Haddad D, McVeigh R, et al. Reference sequence (RefSeq) database at NCBI: current status, taxonomic 
expansion, and functional annotation. Nucleic Acids Res. Oxford University Press. 2015;44:D733-45.

27. Rinke C, Schwientek P, Sczyrba A, Ivanova NN, Anderson IJ, Cheng J-F, et al. Insights into the phylogeny and coding potential of microbial dark matter. Nature. Nature Publishing Group; 2013;499:431.

28. Konstantinidis KT, Ramette A, Tiedje JM. The bacterial species definition in the genomic era. Philos Trans R Soc B Biol Sci. The Royal Society. 2006;361:1929-40.

29. Segata N, Börnigen D, Morgan XC, Huttenhower C. PhyloPhIAn is a new method for improved phylogenetic and taxonomic placement of microbes. Nat Commun. NIH Public Access; 2013;4:2304.

30. Markowitz VM, Mavromatis K, Ivanova NN, Chen I-MA, Chu K, Kyrpides NC. IMG ER: a system for microbial genome annotation expert review and curation. Bioinformatics. Oxford University Press. 2009;25:2271-8.

31. Langmead B, Salzberg SL. Fast gapped-read alignment with Bowtie 2. Nat Methods. Nature Research. 2012;9:357-9.

32. Campanaro S, Treu L, Kougias PG, Francisci D, Valle G, Angelidaki I. Metagenomic analysis and functional characterization of the biogas microbiome using high throughput shotgun sequencing and a novel binning strategy. Biotechnol Biofuels. BioMed Central; 2016;9:1.

33. Anders S, Pyl PT, Huber W. HTSeq-a Python framework to work with highthroughput sequencing data. Bioinformatics. Oxford University Press. 2015; 31:166-9.

34. Mortazavi A, Williams BA, McCue K, Schaeffer L, Wold B. Mapping and quantifying mammalian transcriptomes by RNA-Seq. Nat Methods. Nature Publishing Group; 2008:5:621.

35. Eren AM, Esen ÖC, Quince C, Vineis JH, Morrison HG, Sogin ML, et al. Anvi'o: an advanced analysis and visualization platform for 'omics data. PeerJ. Peer J Inc.; 2015;3:e1319.

36. Robinson MD, McCarthy DJ, Smyth GK. edgeR: a Bioconductor package for differential expression analysis of digital gene expression data. Bioinformatics. Oxford University Press. 2010;26:139-40.

37. Luton PE, Wayne JM, Sharp RJ, Riley PW. The mcrA gene as an alternative to $16 \mathrm{~S}$ rRNA in the phylogenetic analysis of methanogen populations in landfillb. Microbiology. Microbiology Society. 2002;148:3521-30.

38. Pennings JLA, Keltjens JT, Vogels GD. Isolation and characterization of Methanobacterium thermoautotrophicum $\Delta \mathrm{H}$ mutants unable to grow under hydrogen-deprived conditions. J Bacteriol. Am Soc Microbiol. 1998; 180:2676-81.

39. Wasserfallen A, Nölling J, Pfister P, Reeve J, De Macario EC. Phylogenetic analysis of 18 thermophilic Methanobacterium isolates supports the proposals to create a new genus, Methanothermobacter gen. nov., and to reclassify several isolates in three species, Methanothermobacter thermautotrophicus comb. nov., Methano. Int J Syst Evol Microbiol. Microbiology Society. 2000;50:43-53.

40. Zinder SH, Sowers KR, Ferry JG. Methanosarcina thermophila sp. nov., a thermophilic, acetotrophic, methane-producing bacterium. Int J Syst Evol Microbiol. Microbiology Society. 1985;35:522-3.

41. RIVARD CJ, SMITH PH. Isolation and characterization of a thermophilic marine methanogenic bacterium, Methanogenium thermophilicum sp. nov. Int J Syst Evol Microbiol. Microbiology Society. 1982;32:430-6.

42. Maus I, Wibberg D, Stantscheff R, Cibis K, Eikmeyer F-G, König H, et al. Complete genome sequence of the hydrogenotrophic archaeon Methanobacterium sp. Mb1 isolated from a production-scale biogas plant. J Biotechnol. Elsevier. 2013;168:734-6.

43. Denef VJ, Fujimoto M, Berry MA, Schmidt ML. Seasonal succession leads to habitat-dependent differentiation in ribosomal RNA: DNA ratios among freshwater lake bacteria. Front Microbiol. Frontiers. 2016;7:606.

44. Prosser J. Dispersing misconceptions and identifying opportunities for the use of'omics' in soil microbial ecology. Nat Rev Microbiol. Nature Publishing Group; 2015;13:439.

45. Dortch Q, Roberts TL, Clayton JR Jr, Ahmed SI. RNA/DNA ratios and DNA concentrations as indicators of growth rate and biomass in planktonic marine organisms. Mar Ecol Prog Ser Oldend. 1983;13:61-71.

46. Porat I, Kim W, Hendrickson EL, Xia Q, Zhang Y, Wang T, et al. Disruption of the operon encoding Ehb hydrogenase limits anabolic CO2 assimilation in the archaeon Methanococcus maripaludis. J Bacteriol. Am Soc Microbiol. 2006;188:1373-80.

47. Müller B, Sun L, Westerholm M, Schnürer A. Bacterial community composition and fhs profiles of low-and high-ammonia biogas digesters reveal novel syntrophic acetate-oxidising bacteria. Biotechnol Biofuels. BioMed Central; 2016;9:48.
48. Mosbæk F, Kjeldal H, Mulat DG, Albertsen M, Ward AJ, Feilberg A, et al. Identification of syntrophic acetate-oxidizing bacteria in anaerobic digesters by combined protein-based stable isotope probing and metagenomics. ISME J. Nature Publishing Group. 2016;10:2405-18.

49. Nobu MK, Narihiro T, Rinke C, Kamagata Y, Tringe SG, Woyke T, et al. Microbial dark matter ecogenomics reveals complex synergistic networks in a methanogenic bioreactor. ISME J. Nature Publishing Group. 2015;9:171022.

50. Akashi H, Gojobori T. Metabolic efficiency and amino acid composition in the proteomes of Escherichia coli and Bacillus subtilis. Proc Natl Acad Sci. National Acad Sciences. 2002;99:3695-700.

51. Widdel F. Growth of methanogenic bacteria in pure culture with 2-propanol and other alcohols as hydrogen donors. Appl Environ Microbiol. Am Soc Microbiol. 1986;51:1056-62.

52. Thauer RK, Kaster A-K, Seedorf H, Buckel W, Hedderich R. Methanogenic archaea: ecologically relevant differences in energy conservation. Nat Rev Microbiol. Nature Publishing Group. 2008;6:579-91.

53. Hori T, Haruta S, Ueno Y, Ishii M, Igarashi Y. Dynamic transition of a methanogenic population in response to the concentration of volatile fatty acids in a thermophilic anaerobic digester. Appl Environ Microbiol. 2006;72: 1623-30.

54. Treu L, Kougias PG, de Diego-Díaz B, Campanaro S, Bassani I, FernándezRodríguez J, et al. Two-year microbial adaptation during hydrogenmediated biogas upgrading process in a serial reactor configuration. Bioresour Technol: Elsevier; 2018.

55. Treu L, Campanaro S, Kougias PG, Sartori C, Bassani I, Angelidaki I. Hydrogen-fueled microbial pathways in biogas upgrading systems revealed by genome-centric metagenomics. Front Microbiol. Frontiers Media SA. 2018;9.

56. Westerholm M, Roos S, Schnürer A. Syntrophaceticus schinkii gen. nov., sp. nov., an anaerobic, syntrophic acetate-oxidizing bacterium isolated from a mesophilic anaerobic filter. FEMS Microbiol Lett. Blackwell Publishing Ltd Oxford, UK; 2010;309:100-4.

57. Manzoor S, Schnürer A, Bongcam-Rudloff E, Müller B. Genome-Guided Analysis of Clostridium ultunense and Comparative Genomics Reveal Different Strategies for Acetate Oxidation and Energy Conservation in Syntrophic Acetate-Oxidising Bacteria. Genes (Basel). Multidisciplinary Digital Publishing Institute; 2018;9:225

58. Zhuang W-Q, Yi S, Bill M, Brisson VL, Feng X, Men Y, et al. Incomplete Wood-Ljungdahl pathway facilitates one-carbon metabolism in organohalide-respiring Dehalococcoides mccartyi. Proc Natl Acad Sci. National Acad Sciences. 2014;111:6419-24.

59. Kersters I, Maestrojuan GM, Torck U, Vancanneyt M, Kersters K, Verstraete W. Isolation of Coprothermobacter proteolyticus from an anaerobic digest and further characterization of the species. Syst Appl Microbiol. Elsevier. 1994;17: 289-95.

60. Lawson CE, Wu S, Bhattacharjee AS, Hamilton JJ, McMahon KD, Goel R, et al. Metabolic network analysis reveals microbial community interactions in anammox granules. Nat Commun. Nature Publishing Group; 2017:8:15416.

61. Mee MT, Collins JJ, Church GM, Wang HH. Syntrophic exchange in synthetic microbial communities. Proc Natl Acad Sci. National Acad Sciences. 2014; 111:E2149-56.

\section{Publisher's Note}

Springer Nature remains neutral with regard to jurisdictional claims in published maps and institutional affiliations.

\section{Ready to submit your research? Choose BMC and benefit from:}

- fast, convenient online submission

- thorough peer review by experienced researchers in your field

- rapid publication on acceptance

- support for research data, including large and complex data types

- gold Open Access which fosters wider collaboration and increased citations

- maximum visibility for your research: over $100 \mathrm{M}$ website views per year

At $\mathrm{BMC}$, research is always in progress.

Learn more biomedcentral.com/submissions 